\title{
STRATEGI PEMBELAJARAN YANG MENYENANGKAN UNTUK MENGOPTIMALKAN POTENSI SISWA
}

\author{
Mulyono \\ Dosen Tetap Fakultas Tarbiyah UIN Maliki Malang, \\ HP. 081334691166, email: mulyonouin@gmail.com
}

\begin{abstract}
Abstraks
Happens in many countries, basic education is exceedingly oriented to formal academic education. Since children enter TK through SD, they are not given a chance to get an enjoyable learning and full of experience which is the basic of the real growth. The obserbing learning is lost. They learn is not for learning. The school should be formatted to be the most pleasure please for them because they can get many new things. Unfortunately, most of young students feel like in a class "Jail". The trouble is a teacher feels like the most excellent people, most brilliant and understand with the children's condition. Fortunately, nowadays there are many kinds of school that give any kinds alternatives of learning approach and give a lesson enjoyably and full of activities since TK or SD. The enjoyable education approach must be a main sufficient in realize the learning revolution for young student.
\end{abstract}

Key words: approaching, education, enjoyable, young student

\section{Pendahuluan}

"Hidup itu ibarat permainan", demikian kata agamawan, pujangga, dan pemikir sejak zaman Socrates, Plato, Aristoteles, dan pemikir sejak zaman klasik hingga sekarang yang mengemukakan tentang makna hidup tersebut. Dan karena hidup itu ibarat permainan, maka setiap orang harus jadi pemain, bukan jadi penonton. Hanya pemain yang berhak memperoleh nilai, sedang penonton adalah riak dari gelombang yang boleh bertepuk, boleh datang dan pergi sesuka hati. (Nurcholis Huda, 1990).

Karena kehidupan adalah permainan, maka dalam menghadapi kehidupan selayaknya dilandasi dengan hati senang atau ridha dalam 
bahasa agama, namun tidak boleh main-main. Karena barang siapa yang menghadapi permainan dengan main-main, mereka pasti kalah sebelum bertarung, ibarat orang main catur, memahami bahwa catur hanyalah permainan, tetapi selama bermain catur tidak boleh main-main, karena pasti kalah hanya dalam beberapa langkah saja. Konsep itu juga termasuk dalam penyelenggaraan dan pelaksannan pendidikan.

Sebagaimana yang kita amati selama ini, sebagian besar lembaga pendidikan di tanah air belum menjadikan sarana pendidikan yang menyenangkan dan memberikan pengetahuan yang bermakna bagi peserta didik. Saat ini, sebagian sekolah dan madrasah terlalu banyak membebani peserta didik dengan pengetahuan yang banyak, namun tidak bermakna. Tidak heran kalau pengetahuan yang diberikan itu tidak bisa dijadikan landasan nilai hidup dan topangan keterampilan yang berkembang secara dinamis. Akibatnya, jangankan untuk bersaing dengan tenaga kerja asing, peserta didik kita bahkan tidak mampu untuk membantu dirinya agar mandiri. Mutu pendidikan kita saat ini masih sangat jauh tertinggal bila dibanding dengan negara-negara yang sudah maju, seperti Amerika, Australia, Jerman, dan Jepang. Bahkan di kawasan Asia Tenggara pun prestasi kita semakin tertinggal oleh negara tetangga dekat kita sendiri, seperti Malaysia dan Singapura. Malaysia yang dahulu banyak berguru ke Indonesia kini sudah melaju lebih jauh dari Indonesia. Justru sekarang telah banyak warga negara kita yang balik menempuh ilmu ke negara jiran tersebut. Sekolah dan kampus menjadi tempat di mana generasi dididik. Bisa kita bayangkan bagaimana kalau generasi kita tidak mau sekolah karena sekolah tidak lagi menyenangkan. Sekolah menjadi tempat yang membuat orang stres, frustasi, dan menjadi gila, tidak hanya siswa bahkan orang tua siswa. (Beswan Djarum, 2010).

Pembelajaran memang semestinya tidak melulu dilakukan di kelas. Bahkan, dalam proses belajar, inovasi pembelajaran itu harus dilakukan atau mungkin diprioritaskan agar pelajaran yang disampaikan dapat diserap oleh siswa secara maksimal (Republika Online, 9-10-2010). Sebagaimana ditemukan Dryden \& Vos (2002:267), di banyak negara, pendidikan dasar terlalu berorientasi pada pendidikan akademik formal, sejak anak masuk di TK hingga tahun-tahun pertama masuk SD. Anakanak tidak diberi kesempatan untuk belajar dengan menyenangkan dan kaya pengalaman yang mendasari pertumbuhan yang sebenarnya. Keasyikan belajar pun menjadi hilang. Mereka belajar untuk tidak belajar. 
Pendidikan dapat dilakukan di mana saja dengan metode yang menyenangkan. Tidak selalu di dalam kelas dengan guru yang mendominasi proses belajar. Fasilitator Gebyar Apresiasi Karakter siswa (Gebyar Aksi), Yusak Manitis (2009), mengatakan pendidikan dengan model di luar kelas dengan cara menyenangkan sebenarnya sudah diterapkan sejak dulu. Salah satunya pendidikan yang ada di Pramuka. Oleh karenanya, dalam kegiatan Gebyar AKSI, Kementerian Pendidikan Nasional menggandeng Pramuka Indonesia untuk memberikan pendidikan karakter yang dilakukan dengan berbagai motode, seperti permainan, aksi kebangsaan, aksi kepedulian, dan aksi kreativitas. Ada juga program Salam Nusantara yang mencakup perkenalan diri dalam bahasa daerah dan nasional, tampilan budaya daerah, serta presentasi profil daerah. Selain itu, program motivasi juga diberikan kepada siswa, yaitu pembinaan keimanan dan akhlak, pengembangan keseimbangan potensi diri, pembinaan kepercayaan diri, serta aktualisasi kesamaan derajat dan status sosial.

"Pendidikan karakter yang dituangkan melalui permaian di Gebyar AKSi diadopsi dari Pramuka, di dalamnya tidak ada semacam ceramah seperti di dalam kelas, karena kita pakai sistem sharing. Kita buat permainan, nanti mereka sendirilah yang temukan prinsip pelajaran dan makna pendidikan karakternya," demikian penjelasanYusak Manitis saat ditemui Republika, di Taman Wiladatika, Jakarta Timur, pada Ahad, 9 Oktober 2009. (Republika Online, 9-10-2010).

\section{Pendekatan Pendidikan yang Menyenangkan}

Pemerhati masalah anak, Seto Mulyadi (Republika, 25 Mei 2009) menyatakan, seorang guru profesional dalam menjalankan tugasnya di sekolah harus mampu menyenangkan muridnya. Kalau suasana menyenangkan sudah tercipta, maka anak-anak akan lebih semangat dalam menerima pelajaran yang disampaikan oleh gurunya.

Kesadaran akan pentingnya mewujudkan pendidikan yang menyenangkan telah tumbuh di berbagai Negara. Dryden \& Vos (2002:267) melaporkan bahwa sekarang telah tumbuh berbagai jenis sekolah yang banyak memberikan beragam alternatif pendekatan belajar, memberikan pelajaran secara menyenangkan dan kaya aktivitas dari TK ke SD. Sekolahsekolah model tersebut telah dirintis pada awal-awal perkembangannya seperti Sekolah The Classical Academy, dibentuk oleh Maxin Learning Institute di St. Louis Park, di Minnesota AS. Sekelompok kecil guru dan 
murid berkumpul pada 1991 dan menganalisis beberapa metode pengajaran terbaik di dunia. Mereka mengembangkan suatu program pendidikan yang diberi nama Program Maxin's "Best of The Integrated Learning Systems" (sistem Pembelajaran Terpadu Terbaik Maxin). Empat pendiri utama sekolah ini, yaitu: Nancy Nicholson Terry, Nora Flood, Janet Oliver, dan Amira Sewell - telah banyak mengikuti pelatihan Montessori secara ekstensif. Di samping itu mereka banyak menggunakan modelmodel pembelajaran yang mereka dapatkan dari berbagai bahan, lokarya dan pelatihan-pelatihan. Pada 1994 akademi tersebut telah berkembang untuk membimbing para siswa dari TK hingga tingkat SMP.

Demikian juga pendidikan kreatif dan menyenangkan telah dikembangkan pula oleh The Classical Academy yang menggunakan The Writing Way to Reading karya Romaldo Spalding - sebuah program fonik terpadu yang dihubungkan dengan banyak metode Doman (seperti dilakukan Montessori International), program Matematika Jepang, Kumon; Metode Latihan Otak karya Paul Dennison; program Marva Collins Classical Literature - sebuah program multimedia yang menghubungkan sejarah dan seni; dan sejumlah metode belajar cepat yang dapat memberikan stimulasi. Demikian pula The Upper School diadakan oleh Iowa Test of Basic Skills (Ujian Kemampuan Dasar Iowa) bagi seluruh siswa yang dirintis sejak 1993. Dari program ini ditemukan bahwa rata-rata pelajar mengalami peningkatan kemampuan diri sebesar 1,6 tahun dalam jangka enam bulan. Bahkan, beberapa pelajar meraih empat dan lima tahun peningkatan kemampuan di berbagai bidang akademik. (Dryden \& Vos, 2002: 267).

Untungnya, banyak contoh lain terbukti mencapai prestasi yang menggembirakan ketika akal sehat (common sense) dipadukan dengan riset yang baik serta kepala sekolah dan guru yang berdedikasi - dan ketika sekolah diprogram untuk mencapai keberhasilan, bukan kegagalan.

Gordon Dryden dan Jeannette Vos (2002:36) menulis ada 16 kecenderungan utama dalam membentuk dunia di masa depan sehingga dibutuhkan metode belajar baru jika masyarakat luas ingin memetik manfaat di era global saat ini, yaitu: (1) Zaman komunikasi instan. (2) Dunia tanpa batas-batas ekonomi. (3) Empat lompatan menuju ekonomi dunia-tunggal. (4) Perdagangan dan pembelajaran melalui internet. (5) Masyarakat layanan baru. (6) Penyatuan yang besar dengan yang kecil. (7) Era baru kesenangan. (8) Perubahan bentuk kerja. (9) Perempuan sebagai 
pemimpin. (10) Penemuan baru tentang otak yang mengagumkan. (11) Nasionalisme budaya. (12) Kelas bawah yang semakin besar. (13) Semakin besarnya jumlah manula. (14) Ledakan praktik-mandiri. (15) Perusahaan kooperatif. (16) Kemenangan individu.

Salah satu dari 16 kecenderungan masyarakat global di atas adalah nasionalisme budaya. Dengan semakin mengarah ke ekonomi duniatunggal, kita semakin mengembangkan gaya hidup global. Akan tetapi, kita juga mengamati kecenderungan yang berlawanan, yang disebut oleh Naisbitt sebagai nasionalisme budaya. Naisbitt mengatakan "Semakin kita mengglobal dan menjadi saling bergantung secara ekonomi, kita pun semakin bertindak manusiawi; kita semakin menegaskan kekhasan kita, semakin ingin mempertahankan bahasa kita, dan berpegang teguh pada akar dan kebudayaan kita. Walaupun Eropa bergabung secara ekonomi, saya kira bangsa Jerman akan semakin Jerman, dan bangsa Perancis akan semakin Perancis".

Sisi negatifnya jelas: "pembersihan etnis" dan ancaman perang saudara di bekas negara Balkan, Yugoslavia; perang Timur Tengah, sering memiliki konotasi agama; pemberontakan di berbagai bagian dari bekas Uni Soviet; fanatisme ras di berbagai negara (Naisbitt \& Aburdene, 1990). Termasuk sisi negatif munculnya nasionalisme budaya di Indonesia adalah pemisahan diri Timor Timur (1999), pengusiran etnis Madura di Kalimantan Tengah (2001), perang saudara di Maluku, gejolak di Sulawesi, Aceh, Papua dan sebagainya.

Akan tetapi, tantangan positif bagi dunia pendidikan juga tampak jelas. Semakin berkembangnya teknologi, semakin subur pula upaya melestarikan warisan budaya kita - dalam bentuk musik, tarian, bahasa, seni dan sejarah. Di dalam komunitas individual yang mengilhami arahbaru pendidikan, khususnya di antara kelompok minoritas, kita akan melihat prakarsa budaya yang akan berkembang - dan peningkatan harga diri yang luar biasa (Dryden dan Vos, 2002: 73).

Slogan sepatu Nike: (1) Anda belajar berbicara dengan berbicara. (2) Anda belajar berjalan dengan berjalan. (3) Anda belajar bermain golf dengan bermain golf. (4) Anda belajar mengetik dengan mengetik. (5) Anda belajar paling baik dengan mempraktikkannya! (Dryden dan Vos, 2002:162). Thomas Edison mengatakan, "Saya tidak pernah bekerja, 
seharipun, dalam hidup saya. Semuanya adalah keasyikan". (Dryden dan Vos, 2002: 174).

\section{Kiat Melahirkan Ide-Ide Cemerlang}

Sungguh mengejutkan bahwa "mata pelajaran " terpenting justru tidak diajarkan di kebanyakan sekolah: cara menentukan masa depan, cara menciptakan ide-ide baru. Padahal, dunia dewasa ini membutuhkan ideide baru yang revolusioner, lebih dari masa-masa sebelumnya. Ada 12 kiat melahirkan ide-ide cemerlang: (1) Definisikan masalah Anda. (2) Definisikan dan visualisasikan solusi ideal. (3) Kumpulkan fakta-fakta: spesifik dan umum. (4) Hancurkan polanya. (5) Keluarlah dari bidang yang Anda kuasi. (7) Cobalah kombinasi baru. (8) Gunakan seluruh indra anda. (9) Jeda-biarkan pikiran anda mengendap. (10) Gunakan musik atau alam untuk mencapai kondisi relaks. (11) Tidurlah bersamanya. (12) Eureka! Idenya muncul keluar. (13) Periksalah kembali. Catatan: Anda dapat juga membalik langkah 1 dan 2 - mulailah dari mimpi Anda, kemudian definisikan posisi Anda sekarang, dan lanjutkan langkah-langkah untuk menjembatani keduanya. (Dryden dan Vos, 2002:182).

Gordon Dryden mengatakan, "Sebuah ide adalah kombinasi baru dari lemen-elemen lama. Tidak ada elemen baru. Yang ada hanyalah kombinasi-kombinasi baru. (dalam Dryden \& Vos, 2002:184).

Karena suatu ide adalah kombinasi baru dari elemen-elemen lama, pencipta ide terbaik bergulat dengan berbagai kombinasi baru secara terusmenerus. Sekarang, unsur revolusioner telah lahir. Kita dapat menentukan solusi ideal lebih dahulu-baru kemudian menciptakannya. Ini adalah perubahan revolusioner. Karena sebelumnya kita mengarahkan pengetahuan kita untuk menyelesaikan masalah, di dalam batasan pengetahuan kita, kini kita mulai menentukan apa yang ingin kita raih. Lalu kita mengelola hal-hal yang tidak kita ketahui dalam upaya meraih tujuan tersebut. Oliver Wendell Holmes mengatakan: "Pikiran yang telah diperkaya dengan ide-ide baru tidak akan pernah kembali ke kondisi asalnya." (Dryden dan Vos, 2002:186).

Edward de Bono mengatakan, "Berpikir vertikal adalah menggali lebih dalam lubang yang sama. Berpikir lateral adalah menggali di tempat lain." Paul MacCready mengatakan, "Satu-satunya pertanyaan bodoh adalah pertanyaan yang tidak Anda lontarkan". (Dryden dan Vos, 2002:190). 
Gordon Rattray Taylor memiliki kunci: "Keluarlah dari bidang Anda:

(1) Para penemu film berwarna Kodachrome, Leopold Mannes dan Leopold Godowsky, adalah musisi. (2) George Eastman (dari Eastman Kodak) sebelumnya adalah seorang pekerja tata buku di sebuah bank. (3) Ladislo Biro, penemu pena bolpoin, dahulunya adalah seorang patung, pelukis, dan jurnalis. (4) King Camp Gillette (penemu silet cukur yang aman) dahulunya adalah penjual tutup botol keliling. (5) John Boyd Dunlop (penemu ban panas) adalah mantan ahli bedah hewan. (Dryden \& Vos, 2002:192).

Tom Peters mengatakan, "Tak ada alasan untuk tidak menjadi hebat". (Dryden dan Vos, 2002:196). Don Fabun mengatakan bahwa, "Pernahkah Anda berpikir bahwa: (1) Semua buku yang ditulis dalam bahasa Inggris modern hanya terdiri dari pola-pola yang dibentuk oleh 26 huruf. (2) Semua lukisan yang ada dibuat hanya dengan pola-pola dari tiga warna primer. (3) Semua musik yang ada hanyalah pola-pola yang terdiri dari 12 nada. (4) Semua kalimat matematika yang ada hanya terdiri dari 10 simbol. (5) Semua perhitungan yang dilakukan komputer digital hanya dibentuk dari pola-pola yang terdiri dari dua komponen. (6) Oleh karena itu, setiap kali kita membicarakan sesuatu sebagai "hal baru", kita sebenarnya sedang berbicara tentang pola asli dari komponen-komponen yang telah ada. (Dryden dan Vos, 2002:182).

Masaaki Imai mengatakan, "Jika Anda hanya belajar satu kata Jepang dalam hidup Anda, kata itu haruslah Kaizen. Kaizen berarti perbaikan. Kaizen berati perbaikan terus-menerus yang melibatkan setiap orang: manajemen atas, manajer, dan pekerja." 


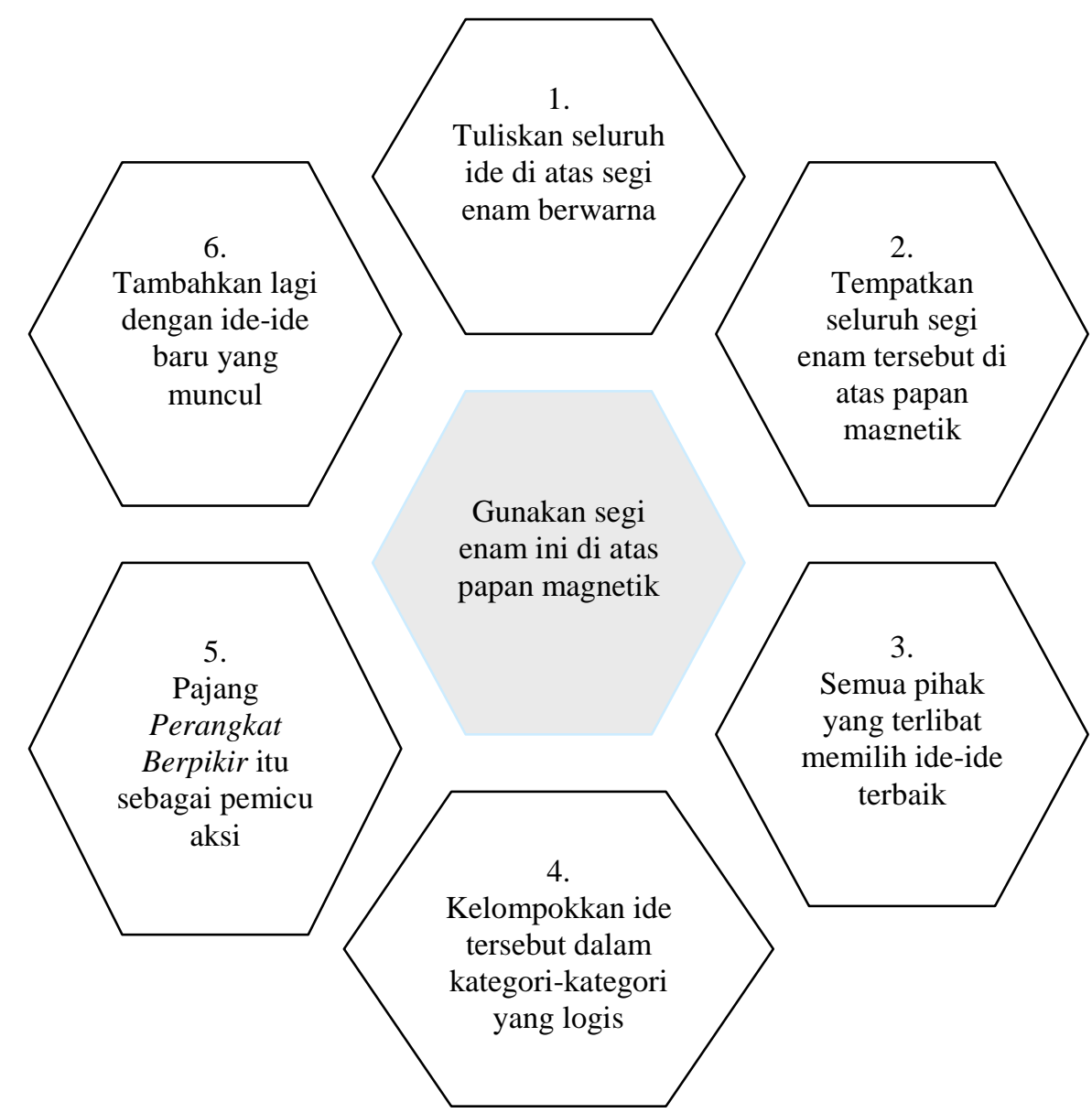

Gambar: Perangkat Berpikir Segi Enam Kaizen

(Sumber: Dryden \& Vos, 2002:206)

David Buffin menemukan teknik 'Buffin Learning' yaitu permodelan segi enam yang digunakan secara luas oleh David Buffin sebagai langkah awal dalam merangsang kemampuan kreatif. Papan besar digunakan untuk pelatihan perusahaan, sedangkan papan yang lebih kecil sedang dikembangkan di rumah dan sekolah.

\section{Aplikasi Pendidikan yang Menyenangkan}

Namun, hal-hal yang tampak tidak menyenangkan itu dapat kita hadapi - apabila kita memang harus bersentuhan dengannya-dengan diri kita yang sudah kita posisikan untuk berada dalam keadaan yang 
menyenangkan (fun). Gordon Dryden dan Dr. Jeannette Vos dalam bukunya Learning Revolution menunjukkan kepada kita cara memposisikan diri kita agar dapat berada dalam keadaan yang fun. Adalah Peter Kline, penulis The Everyday Genius menyatakan bahwa 'Learning is most effective when it's fun': Belajar akan efektif kalau seseorang dalam keadaan senang. Sedang Tony Buzan dari Marlow Inggris, penemu konsep mind mapping (pemetaan pikiran) menyatakan bahwa 'Your brain is like a sleeping giant' : Otak Anda adalah ibarat raksasa tidur".

Kita dapat memadukan pernyataan Kline dan Buzan yaitu kekuatan berpikir akan meraksasa apabila diri kita berada dalam keadaan yang menyenangkan (fun). Menyenangkan berarti seluruh komponen fisik dan nonfisik kita bebas dari tekanan. Menyenangkan berarti kita berada dalam keadaan yang amat relaks, tidak ada sama sekali ketegangan yang mengancam diri kita di sudut-sudut terkecil dalam diri nonfisik dan fisik kita. Menyenangkan juga berarti diri kita berada dalam keadaan yang bebar-benar lepas, bebas, dan luas. Keadaan fun akan melapangkan jalan seseorang dalam mendayagunakan seluruh potensi yang dimilikinya secara optimal. Atau, dalam bahasa yang lain, keadaan fun akan mendorong seseorang untuk bersungguh-sungguh, terlibat, dan asyiik dalam melakukan sesuatu - termasuk dalam belajar. Dalam bahasa psikologi berkaitan dengan emotional intelligence (EQ), keadaan fun adalah keadaan yang berkaitan dengan emosi positif. (Hernowo, dalam Dryden \& Vos, 2002:9-10).

Aplikasi bagaimana mewujudkan pendidikan yang menyenangkan, sebagaimana yang dilaporkan oleh Dian Pratama Jati (23 Juli 2008), salah satunya ditunjukkan oleh Artikel ini saya tulis, karena rasa ketertarikan saya dengan SMP Alternatif Qaryah Thayyibah (QT), sebuah sekolah di ujung timur kota Salatiga, tepatnya dilereng bukit Merbabu, terletak di sebuah desa kecil yang bernama Kalibening. Sebenarnya QT sama dengan sekolah-sekolah lain, tapi ada satu hal yang membedakan QT dengan sekolah lain yaitu suasana pembelajarannya. Di QT, murid harus selalu gembira, terbebas dari tekanan yang membebani. Sebab, mereka percaya suasana yang membebaskan dan menyenangkan akan memunculkan daya inisiatif, inovatif dan kreatifitas dengan maksimal. Selain itu, alam sekitar dijadikan media belajar yang di prioritaskan oleh pendidikan QT, alam bagi mereka adalah laboratorium raksasa, yang tidak akan habis dieksplorasi. Murid secara langsung bersentuhan dengan pertanian, home 
industry, koperasi desa, masyarakat, dan lain sebagainya. Sehingga murid tidak merasa terasing dari daerahnya sendiri. Sekolah ini juga mengutamakan partisipasi dan komunikasi yang baik antara pengelola pendidikan, guru, siswa, masyarakat, dan lingkungannya serta merancang sistem pendidikan yang realistis dan sesuai dengan kebutuhan.

Itulah perbedaan dan kunci keberhasilan dari QT. Jika saja metode pembelajaran di sekolah-sekolah pada umumnya seperti apa yang dilakukan QT, mungkin kita tidak akan melihat ekspresi kelegaan dan kegembiraan siswa ketika bel pelajaran berakhir. Selama ini, sekolah jauh dari kesan asyik dan menyenangkan, yang terjadi di sekolah hanyalah rutinitas. Murid diwajibkan datang ke kelas, mendengarkan penjelasan guru, mencatat, dan diberi tugas. Murid berada dalam suasana pembelajaran yang statis, kaku, membosankan dan tidak menumbuhkan rasa keingintahuan dan kreatifitas siswa. (Dian Pratama Jati, 23 Juli 2008),

Mungkin kita perlu merenungkan kembali makna pendidikan menurut Ki Hajar Dewantara dimana pendidikan adalah daya upaya untuk memajukan budi pekerti, pikiran serta jasmani anak, agar dapat hidup selaras dengan alam dan masyarakatnya. Melalui pendidikan manusia hendaknya menyadari hakikat dan martabatnya, bahwa mereka tak terpisahkan dengan alam lingkungan dan sesamanya. Itu berarti, pendidikan sebenarnya mengarahkan manusia menjadi insan yang sadar akan lingkungan alam maupun sosial sekitarnya.

Namun, yang terjadi pendidikan dewasa ini justru telah meninggalkan alam dan lingkungan. Pendidikan yang diberikan tidak seimbang antara belajar yang berpikir (kognitif) dan perilaku belajar yang merasa (afektif). Anak menjadi kehilangan kepekaan terhadap alam dan lingkungan. Padahal sejatinya belajar bukan hanya berfikir namun mengamati, membandingkan, menyukai, meneliti keadaan alam dan lingkungan juga merupakan proses belajar.

Jika saja sekolah dan guru mampu menciptakan dan mengkomunikasikan metode pembelajaran yang menarik dan siswa dapat mengutarakan dan memilih metode yang diinginkan tentu suasana pembelajaran bisa menjadi menyenangkan. Ketika guru mampu mengemas materi pelajaran dengan games atau observasi, siswa akan tertantang untuk berimajinasi dan berkreasi. Suasana menjadi 
menyenangkan, jauh dari kesan tegang dan kaku seperti yang terjadi di sekolah-sekolah pada umumnya.

Jika saja sekolah dan guru mampu berkomunikasi dengan baik dan menyenangkan, tentu siswa tidak akan takut untuk mengemukakan pendapatnya. Siswa bisa bebas bercerita dan mengkomunikasikan ide maupun gagasannya.

(Dian Pratama Jati, 23 Juli 2008). Jika saja sekolah tidak hanya memberi teori semata namun juga menghadirkan realitas ke hadapan siswa, tentu mereka akan lebih mudah menyerap berbagai macam ilmu dan informasi yang mereka dengarkan, lihat, dan rasakan. Materi pelajaran tidak akan sekedar angin lalu yang mudah terlupakan. Tapi lebih dari itu, siswa dapat melihat sendiri realitas yang terjadi di lingkungan alam dan sosial mereka, siswa tidak akan kehilangan kepekaan terhadap lingkungan alam dan sosial disekelilingnya.

Semoga nantinya kita bisa melihat lebih banyak QT-QT di Indonesia sehingga kita tidak akan menjumpai siswa-siswi yang justru asyik nongkrong di tepi jalan, di warung-warung, di mall, dan di tempattempat yang dianggap menarik lainnya pada jam-jam sekolah. Karena mereka mengganggap sekolah bukan tempat yang asyik dan menyenangkan.

\section{Penutup}

Menghadapi hidup - apa pun bentuk kehidupan yang sedang berada di depan kita - dengan keadaan diri kita yang sedang berada dalam kondisi menyenangkan. Apabila kita mampu menghadapi hidup dengan keadaan diri kita seperti itu, kita akan mampu mengatasi hidup dengan kekuatan-kekuatan menakjubkan yang tiba-tiba hadir di dalam diri kita. Model pembelajaran yang menyenangkan tersebut merupakan modal utama dalam pelaksanaan revolusi belajar pada usia anak yang kemudian berkembang menjadi PAKEM (Pembelajaran yang Aktif, Kreatif, Efektif dan Menyenangkan).

\section{DAFTAR PUSTAKA}


http://www.gugustugastrafficking.org/ Pendidikan Bebas dan Menyenangkan Membentuk Karakter dan Kepribadian, Pontianak, 22 Mei 2009, [Online] Sabtu, 10 Juli 2010.

http://edu-articles.com/ Pakem 1, 29 Januari 2009, [Online] Sabtu, 10 Juli 2010.

Republika OnLine, Mari Mengajar Dengan Cara Menyenangkan, 9-102009, [Tersedia] http:/ / myquran.com/ [Online] Sabtu, 10 Juli 2010.

Gordon Dryden dan Jeannette Vos, Revolusi Cara Belajar (The Learning Revolution), Belajar Akan Efektif Kalau Anda Dalam Keadaan "Fun" Bagian I. Penerjemah: Word ++ Translation Service. Bandung: Kaifa, Cetakan III, 2002, Hal. 37.

John Naisbitt \& Patricia Aburdene, Megatrends 2000. Penerjemah, Drs. F.X. Budijanto. Jakarta: Binarupa Aksara, 1990.

Beswan Djarum - The Official Group \#3, Beswan Pendidikan Belum Menyenangkan?, 2010, [Tersedia] http://www.facebook.com/ / [Online] Sabtu, 10 Juli 2010.

Gordon Dryden, Out Of Th Red, Terbitan William Collins, Auckland, Selandia Baru. Salam Gordon Dryden dan Jeannette Vos, 2002, Ibid, Hal. 184.

Edward de Bono, Pencipta Berpikir Lateral, Wawancara audio, Radio i, Auckland, Selandia Baru.

Tom Peters, The Circle of Innovation. Terbitan Alfred A. Knopf, New York, AS. Gordon Dryden dan Jeannette Vos, 2002, Ibid, Hal. 196.

Don Fabun, Three Roads To Awareness, Terbitan Glencoe Press, Beverly Hills, California, AS. dalam Gordon Dryden dan Jeannette Vos, 2002, Ibid, Hal. 182.

Masaaki Imai, Kaizen: The Key To Japan's Competitive Success. Diterbitkan oleh Random House, 201 East 50th St., New York, NY 10022, AS.

Republika Newsroom, Kak Seto: Guru Harus Bisa Menyenangkan Murid, Senin, 25 Mei 2009 pukul 17:24:00, [Online] Sabtu, 10 Juni 2010.

Dian Pratama Jati, Jika Saja Sekolah Itu Asyik dan Menyenangkan, 23 Juli 2008 - 09:09:41, [Tersedia] http:/ / eduplus.or.id/[Online] Sabtu, 10 Juni 2010. 